\title{
AVALIAÇÃO DA FLEXIBILIDADE DA JORNADA DE TRABALHO E O SEU IMPACTO NO COMPARTILHAMENTO DO CONHECIMENTO
}

\author{
EVALUATION OF THE FLEXIBILITY OF THE WORK JOURNEY AND ITS IMPACT ON \\ KNOWLEDGE SHARING
}

\author{
Leander Luiz Klein \\ Universidade Federal de Santa Maria (UFSM), RS, Brasil \\ E-mail: kleander88@gmail.com \\ Moises Pivetta Cogo \\ Universidade Federal de Santa Maria (UFSM), RS, Brasil \\ E-mail: moises.cogo@ufsm.br \\ Breno Augusto Diniz Pereira \\ Universidade Federal de Santa Maria (UFSM), RS, Brasil \\ E-mail: brenodpereira@gmail.com
}

Recebido em: 20.08.2020 - Aceito em: 16.09.2020

DOI: http://dx.doi.org/10.5902/2526629253282

RESUMO: Este artigo tem como objetivo avaliar o impacto da redução e flexibilização da jornada de trabalho sobre a gestão do conhecimento organizacional. Para tanto, realizou-se um estudo de caso em uma instituição federal de ensino superior (IFES) com os servidores da reitoria, local onde foi realizada a redução e flexibilização de horário de trabalho. Foi realizada uma pesquisa survey com 238 respondentes válidos. O instrumento utilizado para a coleta de dados foi um questionário elaborado no Modelo de Gestão do Conhecimento para a Administração Pública Brasileira de Batista (2012). Adotando essa estratégia, como resultado essencial deste estudo, verificou-se que não há diferenças significativas no compartilhamento do conhecimento entre os grupos que aderiram e não aderiram a flexibilização. Conclui-se que a flexibilização da carga de trabalho não tem impactos positivos na gestão do conhecimento na instituição estudada, pois não há estímulo de sua parte, nem rotinas organizacionais que instiguem o compartiIhamento do conhecimento.

Palavras-chave: Conhecimento; Jornada de Trabalho; Flexibilidade.

ABSTRACT: The objective of this study is to evaluate the impact of the reduction and flexibilization of the working journey on the management of organizational knowledge. In order to do so, a case study was carried out in a federal institu- 
tion of higher education (FIHE) with the servers of the rectory, where the reduction and flexibilization of working hours was made. A survey was conducted with 238 valid respondents. The data collection instrument was a questionnaire elaborated with Knowledge Management Model for the Brazilian Public Administration of Batista (2012). Adopting this strategy, as an essential result of this study, it was found that there were no significant differences in knowledge sharing between the groups that adhered and did not adhere to the flexibilization. It is concluded that the flexibilization of the workload does not have positive impacts on the knowledge management in the studied institution because there is no stimulation of the same and the organizational routines of the same do not instigate the knowledge sharing.

Keywords: Knowledge; Work Journey; Flexibility.

\section{INTRODUÇÃO}

O trabalho em tempo parcial ou de horas reduzidas tem se expandido e alavancado o conhecimento em vários países, como é o caso da França, da Alemanha, do Reino Unido, da Nova Zelândia, do Canadá, dos Estados Unidos e do Japão (Felstead \& Jewson, 1999). Todavia, existem controvérsias no que diz respeito ao real impacto do trabalho de tempo parcial ou de horas reduzidas para trabalhadores e empresas.

A mobilização pela redução da jornada de trabalho sem diminuição de salários faz parte de uma luta histórica de trabalhadores e de organizações representativas de classe (como os sindicatos, os conselhos regionais e as centrais sindicais). Os trabalhadores partem da premissa de que a redução da jornada de trabalho propiciará, além do descanso necessário e da reposição das energias, a ampliação do seu tempo livre e a melhoria da qualidade de vida. Acredita-se, também, que surgirão novos postos de trabalho e, consequentemente, haverá a diminuição do desemprego.

Por outro lado, a esperada "redução da jornada com manutenção do salário mensal" tende, mantendo os demais fatores constantes, a aumentar o custo do trabalho frente aos demais fatores de produção, podendo provocar uma eventual substituição do fator trabalho, que ficaria mais caro frente aos demais. Para que isso não ocorra, faz-se necessário o aumento de produtividade. Ou seja, reduzir a jornada de trabalho não significa necessariamente que as pessoas venham a produzir menos. Pelo contrário, a produtividade poderia ser aumentada mais do que proporcionalmente a diminuição da jornada de trabalho. 
Entretanto, na literatura acadêmica e no contexto brasileiro, desconhece-se estudos que disponibilize informações sistematizadas sobre o trabalho de horas reduzidas e seus impactos para as organizações. Diversos autores têm estudado a diversidade de formas de contratação, e, inclusive, alguns mencionam que uma maneira alternativa, cuja utilização tem crescido, é o trabalho de horas reduzidas, mas sem caracterizá-lo de forma mais cuidadosa e sem apresentar a percepção dos agentes organizacionais envolvidos nesta forma de contratação (Jinkings, 2002).

Assim, torna-se importante compreender melhor o trabalho de horas reduzidas, uma vez que apesar de estar em expansão em vários países, há poucos estudos específicos acerca deste tema, especialmente devido às controvérsias em relação ao seu impacto para funcionários e empregadores, principalmente no setor público. As pesquisas sobre flexibilização no trabalho nesse setor estão longe de se equiparar às pesquisas no setor privado.

A flexibilização da jornada de trabalho também vai ao encontro da nova administração pública, a qual está focada no modelo gerencial, eliminando práticas clientelistas e burocráticas presentes até então na administração pública e que é substituída por práticas gerenciais com foco em resultados e ganho de produtividade. Além disso, percebe-se atualmente um movimento que tem se tornado tendência em muitas universidades públicas federais, tanto por parte dos servidores quanto por parte dos gestores dessas instituições. Essa tendência visa buscar a implementação da ampliação dos horários de atendimento aos seus usuários por meio da flexibilização da jornada de trabalho dos servidores. Este tipo de jornada de trabalho estruturada em escalas de serviço exige dos colaboradores amplo conhecimento dos processos organizacionais, agilidade no atendimento das demandas e ampliação da qualidade dos serviços prestados, de modo que seja justificada a ampliação do horário de atendimento.

Desta forma, este estudo tem como objetivo avaliar o impacto da redução e flexibilização da jornada de trabalho sobre a gestão do conhecimento organizacional. A premissa básica na qual esta pesquisa se sustenta, alicerça-se sobre o seguinte argumento: a redução da jornada de trabalho permite uma melhor transferência de conhecimento entre as pessoas, auxiliando o processo de gestão e compartilhamento do conhecimento organizacional, possibilitando, assim, um maior ganho de produtividade.

Assim sendo, este trabalho visa estudar um caso, em que foi implantado a redução da jornada de trabalho, tendo como contrapartida a necessidade de compartilhamento de conhecimento entre todos os envolvidos nos setores. Busca-se, 
assim, verificar se houve um maior compartilhamento do conhecimento entre os membros da instituição dado a redução da jornada de trabalho proposta.

\section{GESTÃO DO CONHECIMENTO NA ADMINISTRAÇÃO PÚBLICA}

O conhecimento organizacional na administração pública pode ser armazenado de várias formas, incluindo a mente humana, como documentos, políticas e procedimentos e compartilhado entre os indivíduos por meio de conversas, treinamentos, programas de aprendizagem e relatórios (Sabherwal \& Becerra-Fernandez, 2003). Mas o conhecimento é criado pela aprendizagem dos indivíduos por meio de suas percepções e, posteriormente, partilhado e combinado com outros conhecimentos. A sua valorização para as organizações públicas fica evidente na sociedade contemporânea, quando é discutida por diversos estudiosos sobre a gestão deste ativo intangível, como Argote e Miron-Spektor (2011), Hartung e Oliveira (2013), Amayah (2013), Pokharel e Choi (2015), entre outros.

De acordo, com Hartung e Oliveira (2013) a gestão do conhecimento é uma estrutura que pode auxiliar os administradores no tratamento de ativos intelectuais, estimulando ações e comportamentos que possibilitam o reconhecimento do conhecimento necessário para a organização tanto pública quanto privada, proporcionando que este seja adquirido, criado, compartilhado e utilizado para atingir os objetivos da organização. Os autores destacam que a gestão do conhecimento pode ser uma forma pela qual as organizações possam reconhecer os conhecimentos necessários para maximizar a produtividade e a eficiência a longo prazo. Argote e Miron-Spektor (2011) discorrem que o conhecimento organizacional é formado por experiências, valores e informações contextualizadas, como também por interpretação e julgamento do sujeito, que possibilitam a manifestação de mudanças cognitivas, podendo incluir componentes explícitos e tácitos, incluindo os indivíduos e as rotinas organizacionais.

No entanto, de acordo com He, Baruch e Lin (2014), a disponibilidade de conhecimento organizacional não assegura sua utilização pelos indivíduos da organização. Isto porque, por vezes, os conhecimentos necessários para diversas atividades podem não serem percebidos e identificados pelos indivíduos ou, muitas vezes, não são compartilhados por eles.

Ramayah, Yeap e Ignatius (2014) destacam que o compartilhamento do conhecimento deve ser foco central da discussão que envolve o entendimento de sua gestão como ação organizacional e, por sua vez, possibilita a utilização desse conhecimento em benefício dos objetivos organizacionais. Pokharel e Choi (2015) 
discorrem que para que ocorra o compartilhamento do conhecimento é fundamental que sejam facilitadas situações rotineiras de aprendizagem.

Nesse sentido, considerando uma integração entre o conhecimento e a administração pública, Heizig (2009) afirma que sob este aspecto "inserem-se práticas distintas e interligadas dentro de um modelo de gestão, cujo objetivo é meIhorar o desempenho organizacional, por meio da retenção, disseminação, compartilhamento e criação de novos conhecimentos". Os processos de criação do conhecimento são abordagens amplas, nas quais o conhecimento é descoberto, capturado, compartilhado ou aplicado (Sabherwal \& Becerra-Fernandez, 2003). Segundo Nonaka e Takeuchi (1997) e Batista (2012), a criação do conhecimento diz respeito a um conjunto de ações que possibilitam a criação de novos conhecimentos, resultantes da interação entre os sujeitos, passando do nível do indivíduo para a mais alta esfera organizacional, principalmente nas organizações públicas.

A internalização é o processo que auxilia a conversão do conhecimento explícito em tácito. O conhecimento explícito pode ser incorporado na ação e na prática de modo individual, em situações virtuais, lendo ou ouvindo histórias ou por meio de simulações ou experimentos. Em contraponto, a externalização envolve a expressão do conhecimento tácito e sua tradução em formas compreensíveis para que outros possam entender. A externalização conta com técnicas para expressar ideias ou elementos como palavras, conceitos, imagens, linguagem figurada, raciocínio indutivo/dedutivo ou inferência criativa e desta forma permite a tradução do conhecimento pessoal ou profissional em formas explícitas que são fáceis de entender (Nonaka \& Takeuchi, 1997; Sabherwal \& Becerra-Fernandez, 2003). Na esfera pública, esse processo ainda é muito pouco compreensível, inibindo em muitos momentos a manutenção e publicitação do conhecimento.

Ressalta-se, dessa forma, que as organizações públicas apresentam dificuldades na propagação e circulação do conhecimento, com aparente desinteresse dos profissionais em compartilhar suas práticas e experiências bem sucedidas. Segundo Karl Wiig (2000), na administração pública as dificuldades se apresentam por muitos motivos, conforme demonstrado na seção a seguir.

\subsection{Dificuldades da gestão do conhecimento na administração pública}

Karl Wiig (2000) argumenta que a viabilidade e o sucesso de qualquer sociedade são, em grande parte, uma função de como seus recursos podem ser aproveitados, tais como os recursos naturais, localização geográfica, capacidade de gerir pessoas e recursos como capital intelectual. Ressalta, também, a impor- 
tância e a complexidade da Administração Pública em qualquer sociedade, uma vez que esta determina sua cultura e qualidade de vida. E ainda, uma atuação ineficiente da administração pública poderá levar a sociedade à decadência. Essa ineficiência passa também pela dificuldade de compartilhamento da gestão do conhecimento, segundo o referido autor.

$\mathrm{Na}$ Gestão do Conhecimento, as ferramentas e sistemas de informações não são os elementos mais importantes, mas sim os recursos humanos. Este insumo é essencial e também o mais crítico, pois os empregados/servidores são pouco incentivados a compartilhar seus conhecimentos uns com os outros, o que impossibilita que os processos organizacionais e o próprio setor sejam beneficiados pelo compartilhamento de ideias (Nonaka \& Takeuchi, 1997).

Os desafios públicos precisam de soluções inovadoras para lidar com a demanda da sociedade. As organizações públicas têm, ao mesmo tempo, a vantagem e a desvantagem da perenidade. A vantagem é que seus servidores ainda têm sua vida profissional amplamente ligada à organização e a sua evolução, o que facilita o compartilhamento e a retenção de conhecimento. A visível desvantagem é que a ausência de competição, o risco de falência ou a perda de mercado causam certa acomodação, o que leva a uma perda do senso de urgência em termos de capacitação, criação de conhecimento e inovação (Nonaka \& Takeuchi, 1997).

Ramayah, Yeap e Ignatius (2014) complementa que, por razões específicas das leis, nas organizações de esfera pública o conhecimento está intimamente ligado a uma função ou cargo específico, ao contrário do que acontece no setor privado, já que servidores e funcionários públicos prestam concurso público para um determinado cargo, de forma que, muitas vezes, são impossibilitados, legalmente, de exercerem outra atividade a não ser que realizem um novo concurso. A consequência indesejada que isso gera é que a visão do indivíduo fica muito mais amarrada ao cargo e à função que ele exerce do que às suas competências e potenciais, caso esses estejam fora dos limites das atribuições que o cargo lhe confere. Este fator não pode ser visto como uma vantagem, pois numa sociedade em que o aprendizado contínuo, a lateralidade e a flexibilidade são importantes características de quem trabalha com conhecimento, o vínculo estreito com o cargo não é algo desejável.

Segundo Karl Wiig (2000), dentre as principais dificuldades para o compartiIhamento da gestão do conhecimento na administração pública estão: inexistência de indicadores; dificuldade de adquirir o conhecimento não-documentado; deficiências de capacitação dos funcionários; baixa compreensão sobre gestão do conhecimento na organização; falta de tempo ou de recursos para compartilhá-lo de forma concreta na rotina diária; falhas de comunicação; oposição de certos grupos 
de funcionários/cultura organizacional de resistência a mudanças; receio de que outros órgãos - públicos em geral - possam ter acesso a informações sigilosas/ confidenciais; deficiências na infraestrutura computacional; entre outras.

$\mathrm{Na}$ sociedade do conhecimento, ao contrário, os indivíduos passam a ser vistos de forma mais ampla, em todo o seu potencial técnico e criativo, pelo acúmulo de suas experiências ao longo de sua vida e carreira e pelo seu potencial de se engajar em diferentes tipos de comunidades de aprendizado, práticas e projetos, além do seu perfil comportamental que pode lhe conferir outras vantagens e oportunidades. Neste contexto é fácil tornar a Gestão do Conhecimento no setor público apenas mais um processo burocrático, uma tarefa adicional e desestimulante para os funcionários, e com isso não agregar valor algum para a sociedade.

Em geral, as esferas da administração pública não possuem uma cultura e um ambiente voltados para a aprendizagem organizacional e/ou inovação e, com raras exceções, também não incentivam a educação continuada de seus servidores (Sabherwal \& Becerra-Fernandez, 2003). Ao contrário do que se observa na iniciativa privada, trabalhadores do setor público devem dar conta de tarefas mais triviais com maior carga burocrática, isto aparece tanto em contexto nacional quanto mundial e esta demanda pode prejudicar a produtividade dos trabalhadores, gerar frustrações e criar uma tendência a realizar apenas as exigências mínimas de trabalho. Este déficit reflete, principalmente, numa menor amplitude e qualidade do atendimento às demandas sociais e prestação precária e onerosa de serviços públicos.

Segundo Karl Wiig (2000) é importante que a administração pública desenvolva sua própria capacidade de trabalhar a Gestão do Conhecimento, não de forma a se tomar uma cópia do setor privado, mas criando o seu movimento estratégico, esforçando-se por inovar em conformidade com a sua própria identidade e especificidade em trabalhar o conhecimento. Para que as dificuldades de implantação sejam superadas são vários os aspectos que devem ser trabalhados como por exemplo: a participação no processo da alta administração, o trabalho de uma cultura organizacional com os funcionários, as práticas de gestão de recursos humanos, o impacto dos sistemas de informação e mensuração de resultados, as alianças estratégicas, entre outros. Esta abordagem reflete a compreensão de que a Gestão do Conhecimento implica, necessariamente, na coordenação sistêmica de esforços em vários planos: organizacional e individual; estratégico e operacional; normas formais e informais. 


\section{MÉTODO DE TRABALHO}

Como o tema em questão trata da gestão do conhecimento no âmbito da gestão pública, faz-se necessário um maior detalhamento das atividades e dos processos que envolvam o conhecimento neste ambiente. Há, ainda, o propósito de responder questionamentos, como: (a) De que forma o conhecimento é criado? (b) Como o conhecimento é desenvolvido e mantido? (c) Como ocorre o compartilhamento do conhecimento entre os servidores? (d) Quais as ferramentas disponíveis na organização que viabilizam a Gestão do Conhecimento?

Preliminarmente, foi realizada uma pesquisa bibliográfica com a temática da Gestão do Conhecimento na Administração Pública, que abrangeu artigos científicos, livros, teses e dissertações. Essa pesquisa teve a finalidade de ampliar o conhecimento sobre o assunto, visando a apresentação de diferentes enfoques e pontos de vista de pesquisadores.

O presente estudo tem o caráter descritivo, visto que, na visão de Collis e Hussey (2005), esse tipo de pesquisa apresenta o comportamento dos fenômenos e é utilizada para verificar e obter informações acerca das características de certo problema ou questão.

Dessa forma, esta análise utilizou como estratégia de pesquisa o estudo de caso, que segundo Collis e Hussey (2005, p. 72), "é um exame extensivo de um único exemplo de um fenômeno de interesse". Para Graham (2010), os estudos de caso fornecem à administração pública uma ferramenta importante para a exposição de problemas de modo que os alunos, profissionais ou docentes podem receber benefícios expressivos. Na visão de Ventura (2007), o estudo de caso é favorável para a exploração de novos comportamentos ou procedimentos ou novas descobertas, pois tem o papel de construir teorias e gerar hipóteses.

Para isto, foi realizada uma pesquisa de caráter quantitativo, a qual contou com a colaboração de servidores de uma instituição de ensino federal. Para a sua realização, precisou-se de um período de aproximadamente 60 dias. Especificamente, os participantes que compuseram este estudo foram os servidores dos setores da Reitoria dessa instituição (local onde foi realizada a redução e flexibilização de horário de trabalho). A reitoria conta com 616 servidores. A amostra mínima para a pesquisa proporcionar um erro amostral de $0,05 \%$ deveria ser de 238 participantes. Como a pesquisa obteve o retorno de 257 servidores, o resultado da amostra pode ser considerado significativo neste estudo.

$\mathrm{O}$ instrumento de pesquisa adotado para a coleta de dados foi um questionário, com o total de 45 questões dispostas em duas partes e distribuídas em 
quatro páginas. A primeira parte compreende a caracterização do perfil dos respondentes, com 11 questões relacionadas aos aspectos socioeconômicos, a saber: idade; gênero; estado civil; escolaridade; setor de trabalho/lotação; tempo de trabalho na instituição; existência de função de chefia ou cargo de direção; renda média familiar; adesão ao processo de flexibilização de jornada de trabalho; tempo de adesão ao processo de flexibilização de jornada de trabalho do setor em que o servidor está lotado; e por último avaliação do processo de flexibilização de jornada de trabalho na IES.

A segunda parte do questionário foi formada pelo instrumento de pesquisa "Modelo de Gestão do Conhecimento para a Administração Pública Brasileira" de Batista (2012). Utilizou-se este modelo, pois ele foi concebido exclusivamente para a aplicação na área das organizações públicas, bem como se trata de um instrumento de análise da Gestão do Conhecimento atual e tem sido utilizado por diversos pesquisadores em gestão pública. Além disso, possui um relevante nível de aplicabilidade, pois não é um questionário extenso e contém uma linguagem acessível aos respondentes.

O modelo de Batista (2012) é composto por conjuntos de 6 assertivas distribuídas em 7 critérios, sendo eles: 1 - Liderança em GC; 2 - Processos; 3 - Pessoas; Tecnologia; 4 - Processos de Conhecimento; 5 - Aprendizagem e Inovação; e, 6 - Resultados da GC. Desse modo, totalizam-se 42 itens referentes aos 7 critérios do modelo de Batista (2012).

Os questionários foram entregues diretamente aos servidores nos setores de trabalho e apanhados na semana seguinte. A participação dos servidores ocorreu de forma voluntária, mediante o preenchimento do questionário anônimo, preservando, assim, a identidade dos respondentes.

Após a aplicação do questionário, os dados foram tabulados utilizando-se o software Microsoft Office Excel 2007 e as análises realizadas por meio dos softwares IBM SPSS Statistics 20.0 (Statistical Package for the Social Sciences) e Microsoft Office Excel 2007. Dessa forma, a análise dos dados do perfil sociodemográfico e da percepção do impacto da flexibilização de jornada de trabalho na IES ocorreu com a apresentação de dados estatísticos descritivos (médias, percentuais, desvio-padrão, teste T, Alfa de Cronbach e frequências).

Posteriormente, os dados obtidos foram analisados com a aplicação do Modelo de Gestão do Conhecimento para a Administração Pública Brasileira, de Batista (2012). Em seguida, foi feito um levantamento das repostas obtidas para os 7 critérios de avaliação, sendo que cada conjunto de respostas representa a situação do critério 
avaliado em termos de Gestão do Conhecimento para a organização (Batista, 2012). Para tanto, esta etapa também se utilizou de técnicas estatísticas descritivas.

\section{APRESENTAÇÃO DO CASO}

O caso estudado foi uma Instituição de Ensino Superior, localizada no estado do Rio Grande do Sul e fundada na década de 1960, a Universidade Federal de Santa Maria. Esta organização possui quatro campis distantes da sede e está vinculada ao Ministério da Educação e Cultura. Delimitou-se o foco da pesquisa na Administração Superior desta organização, que é representada pelos Órgãos de Direção e Assessoria (Pró-Reitorias), Gabinete do Reitor e Vice-Reitor, Auditoria Interna, Órgãos Executivos da Administração Superior, Órgãos Suplementares Centrais, todos vinculados à Unidade Reitoria da UFSM que é o órgão da Administração Superior responsável por coordenar e supervisionar todas as atividades universitárias.

A Reitoria da Universidade Federal de Santa Maria possui 749 servidores que devem executar, coordenar e superintender todas as atividades universitárias, sendo que nos setores participantes da pesquisa, ou seja, que adotaram o processo de flexibilização, estão lotados 616 servidores. A escolha dos servidores da reitoria se deve pelo fato de eles terem a opção da flexibilização de suas subunidades.

A flexibilização da jornada de trabalho na UFSM ocorreu após a aprovação da resolução interna que estabelece critérios mínimos para subsidiar o dirigente máximo na aplicação da flexibilização da jornada de trabalho, no que concerne às unidades e subunidades. Tal resolução foi aprovada depois da crescente demanda de solicitações à Administração Central de flexibilização da jornada de trabalho pelas unidades/subunidades integrantes da estrutura organizacional da UFSM.

De acordo com a resolução, a jornada de trabalho poderá ser flexibilizada para 6 (seis) horas diárias e 30 (trinta) horas semanais, sem intervalo para refeições e com atendimento em período igual ou superior a 12 (doze) horas nos locais previamente autorizados pelo dirigente máximo da UFSM, considerando atendimento ao público ou horário noturno.

São critérios mínimos para abertura de processo administrativo de solicitação da aplicação da flexibilização da jornada de trabalho na unidade/subunidade, cumulativamente:

a) necessidade justificada de execução, pela unidade/subunidade, de atividades contínuas de regime de turnos ou escalas, em período igual ou superior a doze horas ininterruptas, em função de atendimento ao público ou trabalho no período noturno; 
b) compromisso com a preservação e melhoria da qualidade do atendimento ao público, com os mesmos recursos atualmente disponíveis;

c) estudo da viabilidade da implementação, com a apresentação prévia das escalas de serviço a serem adotadas no setor solicitante, justificando o horário de início e encerramento do expediente; e

d) cumprimento da jornada estipulada independentemente de afastamentos legais e eventuais de Técnico-Administrativos em Educação, observada a legislação vigente.

Ficou estipulado o prazo de seis meses, prorrogáveis por igual período, a contar o tempo de experiência para a flexibilização da carga horária daquele setor que obteve autorização ou determinação, sendo que a manutenção da flexibilização dependerá de avaliação de Comissão Institucional Permanente Paritária composta pelos diferentes segmentos da Comunidade Universitária.

A avaliação do período de experiência será constituída da comprovação dos resultados obtidos por cada um dos critérios que determinaram a sua autorização. Primeiro, a avaliação da necessidade de flexibilização da jornada de trabalho deverá ser comprovada pelo setor mediante relatórios de atendimento ao público durante a jornada de trabalho ininterrupta. Segundo, deverá ser demonstrado a preservação ou melhoria da qualidade do atendimento ao público comprovado pelo setor por meio de entrevistas/questionários preenchidos pelos usuários dos serviços.

Nesse contexto de flexibilização de jornada de trabalho, o questionário foi aplicado a cerca de $30 \%$ dos servidores lotados na Reitoria da UFSM até a presente data. Pelos critérios propostos fica clara a necessidade de manutenção e/ou melhoria da qualidade dos serviços propostos. Os setores que antes funcionavam 6 horas, começaram a funcionar, com a flexibilização, 12 horas. Todavia, houve a necessidade de todos os funcionários/servidores exercerem todas as atividades do setor. Esta seria a condição necessária para o sucesso do modelo proposto. Ou seja, faz-se necessário que os setores se articulem no sentido de que sempre haja servidores habilitados a prestar o atendimento requerido, independentemente do turno de trabalho da ocorrência. Para tanto, os conhecimentos que antes eram exclusivamente dominados por um ou poucos servidores, agora devem ser compartilhados de maneira efetiva, a fim de que todos estejam capacitados para desenvolver as atividades necessárias, garantindo assim, o sucesso do processo de implementação da flexibilidade do trabalho com melhoria da qualidade do atendimento. 


\section{ANÁLISE DOS RESULTADOS}

Inicialmente, o instrumento de pesquisa compreende 8 questões que estão relacionadas ao perfil dos respondentes, segundo dados sociodemográficos, como: idade, gênero, estado civil, escolaridade, setor de trabalho, tempo de trabalho na UFSM, existência de cargo de chefia ou cargo de direção e renda média familiar.

Diversos setores de trabalho vinculados à Reitoria da Universidade Federal de Santa Maria colaboraram com a pesquisa. Em relação ao total de participantes da pesquisa na UFSM, o setor que apresentou o maior número de respondentes foi a Pró-Reitoria de Gestão de Pessoas (PROGEP) com 28\%; já o Centro de Processamento de Dados (CPD) foi representado por 8,9\% dos respondentes; $8,2 \%$ exercem suas atividades na Pró-Reitoria de Infraestrutura (PROINFRA); 7,8\% são do Departamento de Materiais e Patrimônio (DEMAPA); e 6,6\% trabalham no Departamento de Contabilidade e Finanças (DCF). A Editora e a Auditoria Interna foram os setores que tiveram menores participações na pesquisa realizada, ambos com $0,80 \%$, sendo apenas dois respondentes de cada local.

Na Figura 1, apresenta-se uma síntese do perfil dos servidores da UFSM pertencentes às unidades vinculadas à Reitoria, com o intuito de destacar os fatores mais relevantes.

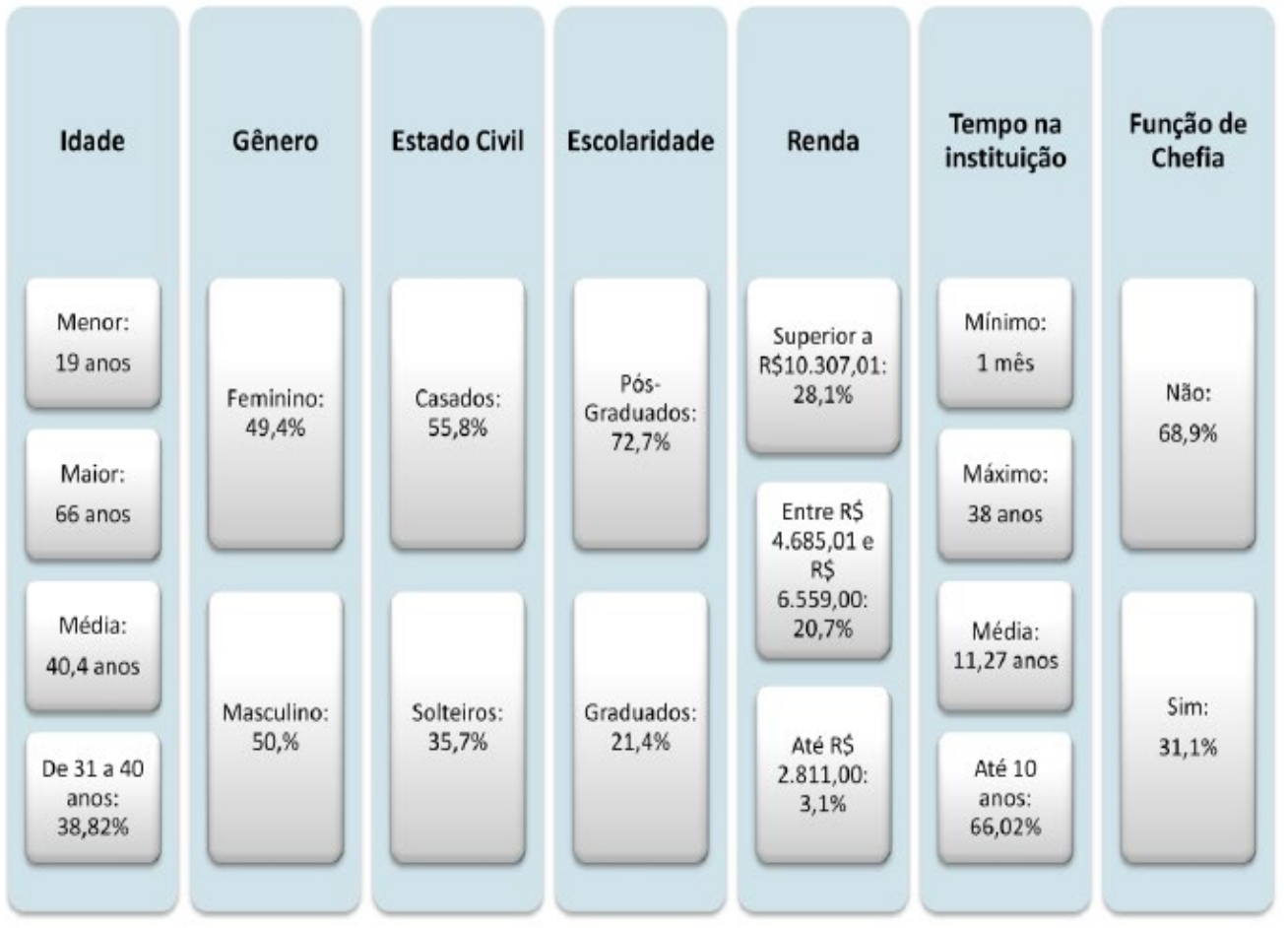

Figura 1 - Síntese dos resultados do perfil sócio demográfico Fonte: Elaborado pelos autores. 
Sobre a Figura 1, pode-se verificar que, em relação à idade dos respondentes, a menor identificada foi de 19 anos e a maior de 66 anos, sendo que a média encontrada foi de 40,4 anos, com um desvio-padrão de 11,06; o que demonstra respostas bastante heterogêneas. Os servidores que possuem idade até 30 anos representam 18,04\% dos pesquisados e 17,65\% pertencem a escala de 41 a 50 anos. A maioria dos respondentes possui entre 31 a 40 anos (38,82\%), bem como outra parcela representativa encontra-se na faixa etária acima de 50 anos $(25,49 \%)$. Isso pode demonstrar que uma parcela significativa do quadro de servidores pesquisados da instituição já possui ou está prestes a cumprir os requisitos para se aposentar.

Diante disso, percebe-se que uma parcela significativa do quadro de servidores da instituição, mais de $43 \%$ dos pesquisados, encontra-se em uma faixa etária acima de 40 anos de idade. Dessa forma, percebe-se que existem muitos colaboradores com experiências e conhecimentos a compartilhar, bem como verifica-se um expressivo ingresso de novos servidores na instituição, uma vez que mais de $56 \%$ dos respondentes possui menos de 40 anos de idade. Desse modo, cabe à organização disponibilizar ferramentas e instituir práticas para que os servidores mais experientes possam disseminar seus conhecimentos para os mais jovens.

Quanto ao gênero, há um equilíbrio entre os 257 respondentes da pesquisa, pois $49,4 \%(n=127)$ pertencem ao gênero feminino, enquanto que 50,6\% $(n=130)$ são do gênero masculino. Ainda, verificou-se que a maioria dos respondentes estão casados ou possuem união estável (55,8\%); outros 35,7\% são solteiros; $5,4 \%$ são separados; e menos de $2,5 \%$ são viúvos ou possuem outro tipo de estado civil como, por exemplo, divorciados.

Com relação ao nível de escolaridade, apenas $1(0,4 \%)$ pesquisado informou ter Ensino Fundamental como maior nível completo; $5,4 \%(n=14)$ possuem Ensino Médio ou Técnico; 21,3\% ( $n=55)$ têm Ensino Superior; 38,4\% ( $n=99)$ informaram possuir Especialização; 30,6\% ( $n=79)$ têm Mestrado; e 3,5\% (n=9) Doutorado. Salienta-se que a maioria (72,7\%) dos respondentes, 187 dos 257, possui escolaridade no nível de Pós-graduação stricto ou lato sensu, indicando um bom índice de qualificação profissional dos servidores.

Nesse contexto, constata-se que o quadro de servidores públicos da UFSM está alicerçado em altas qualificações e possui totais condições de aprender e incorporar as habilidades e capacidades necessárias à implementação de um projeto de Gestão do Conhecimento institucional. Por mais variadas que sejam as 
áreas de conhecimento das formações, com um índice de $72,7 \%$ de pós-graduados e mais $21,4 \%$ de graduados, totalizando $94,1 \%$ dos respondentes com pelo menos nível superior completo, percebe-se que a representatividade do nível de qualificação dos servidores da UFSM denota um fator positivo para o sucesso da implementação de uma política de Gestão do Conhecimento na instituição.

O tempo de serviço na instituição variou dentre os respondentes, de apenas 1 mês a até 38 anos de trabalho, com uma média de 11,27 anos e desvio-padrão de 11,46, demonstrando uma grande variabilidade nas respostas obtidas. Também, verificou-se que uma significativa parcela $(66,02 \%)$ dos colaboradores possuem 10 anos de serviço ou menos, o que demonstra a ocorrência de uma renovação no quadro funcional da Universidade Federal de Santa Maria. Quando questionados se possuem Função de Chefia ou Cargo de Direção, 68,9\% dos participantes afirmaram que "Não"; e 31,1\% declararam que "Sim".

\subsection{Percepção do impacto da flexibilização de jornada de trabalho}

Considerando os setores pesquisados, 29,2\% $(n=75)$ dos colaboradores aderiram aos processos de flexibilização de jornada de trabalho, enquanto os outros $70,8 \%$ ( $n=182)$ não participam da flexibilização. Outrossim, cerca de $42 \%$ $(n=108)$ dos servidores participantes da pesquisa estão inseridos em ambientes de trabalho organizados sob o regime de flexibilização da jornada de trabalho, quais sejam, Departamento de Materiais e Patrimônio - DEMAPA, Pró-Reitoria de Assuntos Estudantis - PRAE, Pró-Reitoria de Gestão de Pessoas - PROGEP e Pró-Reitoria de Infraestrutura - PROINFRA.

No entanto, não é possível afirmar que todos os servidores que não aderiram ao processo de flexibilização não o fizeram por rejeitar a proposta. Há setores de trabalho que não realizam atendimentos, condição necessária para solicitação da flexibilização; há servidores com função de chefia ou cargo de direção, os quais não podem ter jornada de trabalho flexibilizada; bem como há locais de trabalho nos quais não é possível estruturar uma ampliação dos horários de atendimentos, tendo em vista a falta de servidores para cumprir as escalas adequadamente.

Desse modo, o resultado de $70,8 \%$ de servidores que não aderiram ao processo de flexibilização não representa uma rejeição da maioria quanto à modificação da jornada e ampliação do horário de atendimento, mas sim um dado representativo dos locais de trabalho onde não houve solicitação de flexibilização de jornada; ou, houve solicitação e ainda não foi autorizada a implantação da nova jornada; ou, simplesmente, o setor de trabalho não é compatível com os requisitos básicos para 
solicitação da flexibilização de jornada de trabalho - ter estrutura de pessoal compatível para a composição das escalas de trabalho e prestar atendimento ao público.

Quanto ao tempo que o setor de trabalho está organizado sob o regime de flexibilização da jornada de trabalho, constatou-se que a PRAE atua assim há cerca de 22 meses e que os outros setores flexibilizados (DEMAPA, PROGEP e PROINFRA) organizam-se desse modo há cerca de 12 meses. Diante disso, averiguou-se que o tempo médio de ocorrência de flexibilização nesses setores é de 12,64 meses, e que outros 149 (58\%) respondentes exercem suas atividades em setores nos quais não há implementação de flexibilização da jornada de trabalho.

Por fim, todos os participantes foram solicitados a avaliar a flexibilização da jornada de trabalho na UFSM. Foram obtidas 251 respostas, sendo que a avaliação mínima atribuída foi 0 (zero) e a máxima 10 (dez), resultando em uma avaliação média de 7,16 pontos, com desvio-padrão de 2,883 . Apesar da média obtida $(7,16)$ poder ser considerada uma nota satisfatória, verificou-se que aproximadamente $14 \%$ dos respondentes avaliaram a flexibilização com nota igual ou inferior a 3 (três) pontos; cerca de 18\% atribuíram uma pontuação entre 4 (quatro) e 6 (seis); e quase $40 \%$ dos respondentes avaliaram o regime de trabalho com nota máxima (10) ou 9 (nove).

Destaca-se que nos setores em que está implementado o regime de trabaIho com flexibilização de jornada, a avaliação média foi de 8,27 pontos. Já nos setores onde não há a implementação, a avaliação da flexibilização foi de 6,36 pontos, ficando um pouco abaixo da média geral.

Face ao exposto, encerra-se neste tópico a análise da primeira parte do instrumento de pesquisa. Dessa forma, a partir do próximo tópico serão apresentados os resultados encontrados com a aplicação do Modelo de Gestão do Conhecimento para a Administração Pública Brasileira de Batista (2012), e as percepções dos respondentes em relação aos critérios questionados e as condições atuais da instituição em relação ao tema.

\subsection{Processo de flexibilização de jornada de trabalho e os construtos do modelo}

Foi realizado um diagnóstico para verificar se houve diferença na percepção entre os servidores que aderiram ao processo de flexibilização de jornada de trabaIho na UFSM e aqueles que não aderiram em relação aos Critérios de análise do modelo adotado na pesquisa. De modo geral, constatou-se que não houve diferença expressiva entre as respostas obtidas. Desse modo, o Critério 1, que corresponde a Liderança em Gestão do Conhecimento, recebeu a média de 2,79 para aqueles que 
aderiram ao processo de flexibilização, enquanto que, para aqueles que não aderiram, a média alcançada foi de 2,71. O que evidencia o posicionamento semelhante de avaliação negativa em relação às lideranças nos diferentes setores analisados, conforme se verifica nos dados apresentados no Quadro 1.

Quadro 1 - Análise comparativa em relação ao Critério "Liderança em GC"

\begin{tabular}{|c|c|c|c|c|c|}
\hline \multirow{2}{*}{ Itens } & \multicolumn{3}{|c|}{ Critério 1 - Liderança em GC } & \multirow{2}{*}{ Teste t } \\
\cline { 2 - 5 } & Média & Desvio-padrão & Média & $\begin{array}{c}\text { Desvio- } \\
\text { padrão }\end{array}$ & $\begin{array}{c}\text { Sig. } \\
\text { (2-tailed) }\end{array}$ \\
\hline $\mathbf{1}$ & 2,81 & 1,0487 & 2,93 & 0,9809 & 0,382 \\
\hline $\mathbf{2}$ & 2,71 & 1,0498 & 2,51 & 1,0297 & 0,165 \\
\hline $\mathbf{3}$ & 2,70 & 0,9025 & 2,57 & 0,9517 & 0,300 \\
\hline $\mathbf{4}$ & 3,16 & 0,9869 & 3,20 & 1,0077 & 0,766 \\
\hline $\mathbf{5}$ & 2,76 & 1,1606 & 2,74 & 1,0605 & 0,910 \\
\hline $\mathbf{6}$ & 2,85 & 1,0487 & 2,68 & 1,0595 & 0,243 \\
\hline $\begin{array}{c}\text { Média } \\
\text { geral }\end{array}$ & $\mathbf{2 , 7 9}$ & & $\mathbf{2 , 7 1}$ & & \\
\hline
\end{tabular}

Fonte: Elaborado pelos autores.

Quanto ao segundo Critério, que está relacionado aos "Processos" de trabalho da organização, houve uma pequena diferença entre as médias obtidas nas respostas dos servidores que aderiram ao processo de flexibilização $(3,05)$ e entre os que não aderiram $(2,94)$. Todavia, em termos populacionais essa diferença não é significativa. Ou seja, com relação ao processo de trabalho, também não se observou nenhuma diferença entre os servidores que aderiram ao processo de flexibilização e os que não aderiram. Os dados são demonstrados no Quadro 2.

Quadro 2 - Análise comparativa em relação ao Critério "Processos"

\begin{tabular}{|c|c|c|c|c|c|}
\hline \multirow{2}{*}{ Itens } & \multicolumn{4}{|c|}{ Critério 2 - Processos } & \multirow{2}{*}{ Teste t } \\
\cline { 2 - 5 } & Média & Desvio padrão & Média & Desvio padrão & $\begin{array}{c}\text { Sig. } \\
\text { (2-tailed) }\end{array}$ \\
\hline $\mathbf{7}$ & 3,25 & 0,8714 & 3,08 & 1,0215 & 0,210 \\
\hline $\mathbf{8}$ & 3,12 & 0,8376 & 2,97 & 0,9939 & 0,259 \\
\hline $\mathbf{9}$ & 3,12 & 0,9925 & 2,93 & 1,0006 & 0,173 \\
\hline $\mathbf{1 0}$ & 2,65 & 0,9853 & 2,51 & 0,9736 & 0,300 \\
\hline $\mathbf{1 1}$ & 2,93 & 0,8595 & 2,84 & 0,9290 & 0,474 \\
\hline $\mathbf{1 2}$ & 2,97 & 0,8695 & 2,94 & 0,9250 & 0,814 \\
\hline $\begin{array}{c}\text { Média } \\
\text { geral }\end{array}$ & $\mathbf{3 , 0 5}$ & & $\mathbf{2 , 9 4}$ & & \\
\hline
\end{tabular}

Fonte: Elaborado pelos autores. 
No que tange ao terceiro Critério, que são as "Pessoas", os resultados obtidos foram similares, correspondendo às médias de 2,64 para aqueles que realizam o processo de flexibilização de jornada de trabalho e de 2,71 para os que não entram nesse conjunto de pessoas, conforme pode-se verificar no Quadro 3.

Desse modo, percebe-se que não houve distinção expressiva entre os diferentes grupos, indicando que há o entendimento de que a instituição realiza de maneira insatisfatória os processos de capacitação e de desenvolvimento de seus colaboradores ao buscar a melhoria de suas habilidades quanto aos conhecimentos e aprimoramentos do desenvolvimento organizacional.

Quadro 3 - Análise comparativa em relação ao Critério "Pessoas"

\begin{tabular}{|c|c|c|c|c|c|}
\hline & \multicolumn{4}{|c|}{ Critério 3 - Pessoas } & \multirow{2}{*}{ Teste t } \\
\cline { 2 - 5 } Itens & Média & Desvio padrão & Média & Desvio padrão & $\begin{array}{c}\text { Sig. } \\
\text { (2-tailed) }\end{array}$ \\
\hline $\mathbf{1 3}$ & 3,61 & 0,8202 & 3,47 & 0,9673 & 0,269 \\
\hline $\mathbf{1 4}$ & 3,12 & 0,9645 & 3,01 & 1,1000 & 0,429 \\
\hline $\mathbf{1 5}$ & 2,19 & 0,8765 & 2,26 & 1,0088 & 0,622 \\
\hline $\mathbf{1 6}$ & 2,43 & 1,0348 & 2,61 & 1,1053 & 0,232 \\
\hline $\mathbf{1 7}$ & 2,55 & 0,9812 & 2,55 & 1,0668 & 0,961 \\
\hline $\mathbf{1 8}$ & 2,73 & 0,9772 & 2,81 & 0,9933 & 0,562 \\
\hline $\begin{array}{c}\text { Média } \\
\text { geral }\end{array}$ & $\mathbf{2 , 6 4}$ & & $\mathbf{2 , 7 1}$ & & \\
\hline
\end{tabular}

Fonte: Elaborado pelos autores.

O quarto Critério foi o que recebeu maior média, referente à "Tecnologia". Os servidores que adotaram o processo de flexibilização apresentaram a média de 3,55; enquanto que, para os demais, se obteve a média de 3,62. No Quadro 4, nota-se que este fato evidencia a preocupação da instituição com relação ao uso da tecnologia em seu ambiente de trabalho, passando a implementar uma infraestrutura de tecnologia de informação, por meio do acesso a computadores e e-mails, intranet e internet, bem como informações atualizadas em seu site. 
AVALIAÇÃO DA FLEXIBILIDADE DA JORNADA DE TRABALHO E O SEU IMPACTO NO COMPARTILHAMENTO DO CONHECIMENTO

Quadro 4 - Análise comparativa em relação ao Critério "Tecnologia"

\begin{tabular}{|c|c|c|c|c|c|}
\hline \multirow{2}{*}{ Itens } & \multicolumn{4}{|c|}{ Critério 4 - Tecnologia } & \multirow{2}{*}{ Teste t } \\
\cline { 2 - 5 } & Média & Desvio padrão & Média & Desvio padrão & $\begin{array}{c}\text { Sig. } \\
\text { (2-tailed) }\end{array}$ \\
\hline $\mathbf{1 9}$ & 3,20 & 0,9005 & 3,24 & 1,0642 & 0,781 \\
\hline $\mathbf{2 0}$ & 3,09 & 0,9469 & 3,12 & 1,0927 & 0,868 \\
\hline $\mathbf{2 1}$ & 3,67 & 1,2229 & 3,87 & 1,0924 & 0,198 \\
\hline $\mathbf{2 2}$ & 3,71 & 1,1714 & 3,94 & 1,0684 & 0,116 \\
\hline $\mathbf{2 3}$ & 3,76 & 0,9563 & 3,78 & 0,9672 & 0,868 \\
\hline $\mathbf{2 4}$ & 3,43 & 1,1410 & 3,47 & 1,0903 & 0,793 \\
\hline $\begin{array}{c}\text { Média } \\
\text { geral }\end{array}$ & $\mathbf{3 , 5 5}$ & & $\mathbf{3 , 6 2}$ & & \\
\hline
\end{tabular}

Fonte: Elaborado pelo autor.

Os Critérios 5 e 6 destacam-se quanto à proximidade das médias obtidas dentre os dois grupos pesquisados. No Critério 5 , referente aos Processos de Conhecimento da instituição, a média alcançada foi de 2,52 para aqueles que aderiram ao processo de flexibilização de jornada de trabalho, ao passo que se teve a média de 2,51 para quem não pertence a esse conjunto de servidores. Já o Critério 6, associado à "Aprendizagem" e "Inovação", apresentou a média de 2,99 para o primeiro grupo e 2,98 para quem não aderiu ao processo de flexibilização; apresentando uma diferença apenas de 0,01 em suas médias nestes dois critérios supracitados, conforme se pode ver nos Quadros 5 e 6.

Quadro 5 - Análise comparativa em relação ao Critério "Processos de Conhecimento"

\begin{tabular}{|c|c|c|c|c|c|}
\hline \multirow{2}{*}{ Itens } & \multicolumn{3}{|c|}{ Critério 5 - Processos de Conhecimento } & \multirow{2}{*}{ Teste t } \\
\cline { 2 - 5 } & Média & Desvio padrão & Média & $\begin{array}{c}\text { Aesvio } \\
\text { padrão }\end{array}$ & $\begin{array}{c}\text { Sig. } \\
\text { (2-tailed) }\end{array}$ \\
\hline $\mathbf{2 5}$ & 2,83 & 1,0316 & 2,84 & 0,9792 & 0,897 \\
\hline $\mathbf{2 6}$ & 2,52 & 0,9913 & 2,53 & 1,0402 & 0,939 \\
\hline $\mathbf{2 7}$ & 2,59 & 1,0410 & 2,49 & 1,0776 & 0,494 \\
\hline $\mathbf{2 8}$ & 2,51 & 1,0369 & 2,31 & 0,9800 & 0,139 \\
\hline $\mathbf{2 9}$ & 2,52 & 1,0314 & 2,48 & 1,0426 & 0,767 \\
\hline $\mathbf{3 0}$ & 2,51 & 1,0702 & 2,56 & 1,0380 & 0,716 \\
\hline Média geral & $\mathbf{2 , 5 2}$ & & $\mathbf{2 , 5 1}$ & & \\
\hline
\end{tabular}

Fonte: Elaborado pelos autores. 
Quadro 6 - Análise comparativa em relação ao Critério "Aprendizagem e Inovação"

\begin{tabular}{|c|c|c|c|c|c|}
\hline \multirow{2}{*}{ Itens } & \multicolumn{3}{|c|}{ Critério 6 - Aprendizagem e Inovação } & \multirow{2}{*}{ Teste t } \\
\cline { 2 - 5 } & Média & $\begin{array}{c}\text { ADERIU } \\
\text { Desvio } \\
\text { padrão }\end{array}$ & Média & $\begin{array}{c}\text { Nesvio } \\
\text { padrão }\end{array}$ & $\begin{array}{c}\text { Sig. } \\
\text { (2-tailed) }\end{array}$ \\
\hline $\mathbf{3 1}$ & 3,19 & 1,0813 & 3,21 & 0,9092 & 0,869 \\
\hline $\mathbf{3 2}$ & 2,80 & 1,0851 & 2,91 & 1,0072 & 0,427 \\
\hline $\mathbf{3 3}$ & 2,67 & 0,9772 & 2,87 & 1,0058 & 0,133 \\
\hline $\mathbf{3 4}$ & 2,91 & 1,1171 & 2,94 & 1,0713 & 0,800 \\
\hline $\mathbf{3 5}$ & 3,09 & 0,9750 & 3,12 & 1,0532 & 0,869 \\
\hline $\mathbf{3 6}$ & 3,08 & 1,0999 & 3,02 & 1,1593 & 0,712 \\
\hline $\begin{array}{c}\text { Média } \\
\text { geral }\end{array}$ & $\mathbf{2 , 9 9}$ & & $\mathbf{2 , 9 8}$ & & \\
\hline
\end{tabular}

Fonte: Elaborado pelos autores.

O Critério 7, referente aos Resultados da Gestão do Conhecimento, possui uma escala de resposta diferenciada por demais critérios, questionando a existência de melhorias na instituição em relação a diversos indicadores (como a eficiência, a efetividade e o impacto das contribuições). Para aqueles que possuem a flexibilização de jornada de trabalho a média identificada foi de 2,56; enquanto que para os demais, a média obtida foi de 2,59, de acordo com o que apresenta o Quadro 7.

Quadro 7 - Análise comparativa em relação ao Critérios "Resultados da GC"

\begin{tabular}{|c|c|c|c|c|c|}
\hline \multirow{2}{*}{ Itens } & \multicolumn{4}{|c|}{ Critério 7 } & \multirow{2}{*}{ Teste t } \\
\cline { 2 - 5 } & Média & Desvio padrão & Média & Desvio padrão & $\begin{array}{c}\text { Sig. } \\
\text { (2-tailed) }\end{array}$ \\
\hline $\mathbf{3 7}$ & 2,36 & 1,0543 & 2,45 & 1,0446 & 0,571 \\
\hline $\mathbf{3 8}$ & 2,41 & 1,0326 & 2,44 & 1,1065 & 0,844 \\
\hline $\mathbf{3 9}$ & 2,61 & 1,0704 & 2,58 & 1,0486 & 0,823 \\
\hline $\mathbf{4 0}$ & 2,51 & 1,0758 & 2,60 & 1,0653 & 0,579 \\
\hline $\mathbf{4 1}$ & 2,61 & 1,0445 & 2,63 & 1,0564 & 0,885 \\
\hline $\mathbf{4 2}$ & 2,61 & 1,0957 & 2,69 & 1,1076 & 0,596 \\
\hline $\begin{array}{c}\text { Média } \\
\text { geral }\end{array}$ & $\mathbf{2 , 5 6}$ & & $\mathbf{2 , 5 9}$ & & \\
\hline
\end{tabular}

Fonte: Elaborado pelos autores.

Além disso, analisando as médias dos itens de cada construto e os valores encontrados para o Teste $t$ demonstrados nos quadros acima, pode-se verificar ainda que, como não há nenhum valor significativo menor de 0,05 , ou seja, não há uma expressiva diferença entre a opinião daqueles que aderiram ao processo de 
flexibilização e aqueles que não aderiram ao processo de flexibilização acerca da Gestão do Conhecimento na UFSM. Desse modo, pode-se conjecturar que não há uma percepção ou uma melhor orientação de gestão do conhecimento nos setores em que há implementação de flexibilização da jornada de trabalho.

A implementação da flexibilização da jornada de trabalho preconiza uma evolução nas relações profissionais, de modo que ocorram maiores interações e trocas de conhecimentos entre os servidores nos diversos setores. Dessa forma, espera-se que, para os ambientes onde há implementação da flexibilização da jornada de trabalho, haja maior empenho e preocupação na estruturação de condições que possibilitem a disseminação dos conhecimentos críticos para todos os colaboradores, a fim de que sejam atendidos os pressupostos de melhoria da qualidade de atendimento e dos serviços prestados, os quais norteiam a modificação da estrutura de trabalho para jornada flexibilizada.

Até o momento, entretanto, verifica-se que não há diferenças significativas na percepção dos respondentes lotados nos setores em que já ocorre a implementação da flexibilização, se comparados com os setores ainda não flexibilizados.

Ademais, o instrumento de pesquisa questionou aos servidores "Como você avalia a gestão do conhecimento na UFSM?", atribuindo uma escala com pontuação de 0 a 10, sendo 0 péssima e 10 ótima. Apesar de pouco significativa, tal resultado surpreende, pois a média das opiniões sobre gestão do conhecimento para os servidores que não possuem jornada de trabalho flexibilizada é um pouco maior $(5,44)$ do que a média das opiniões de servidores que aderiram ao processo de jornada flexibilizada $(5,37)$. Ou seja, da mesma forma das outras questões não se observou nenhuma diferença significativa entre os grupos estudados.

\section{CONSIDERAÇÕES FINAIS}

O fortalecimento da temática de Gestão do Conhecimento no setor público torna-se imprescindível às instituições, visto que o conhecimento adquirido, preservado e compartilhado entre os servidores representa um diferencial competitivo de aprendizagem e de melhoria nos processos de trabalho e de tomada de decisões. Neste sentido, este trabalho teve o objetivo de desenvolver e verificar como a implementação de um processo de flexibilização de jornada de trabalho poderia ser um fator facilitador para a disseminação e compartilhamento de conhecimento na instituição.

Dessa forma, a fim de alcançar o objetivo, foi identificado primeiramente o perfil sociodemográfico dos participantes da pesquisa. Pode-se destacar o estado 
civil "casado" dentre a maioria dos servidores; há aproximado número de homens e de mulheres; o nível de escolaridade de mais de $70 \%$ dos respondentes é de pós-graduação; a idade e o tempo na instituição apresentaram alta variabilidade, com servidores entre 19 e 66 anos; e, tempo mínimo de um mês e máximo de 38 anos atuando na instituição. Além disso, a média de idade dos servidores é de 40,4 anos e tempo de trabalho é de 11,27 anos na UFSM.

Além disso, os servidores foram questionados sobre a sua percepção quanto aos processos de gerenciamento de conhecimento existentes na organização, a fim de identificar como eles visualizam os Critérios de avaliação do Modelo de Gestão do Conhecimento para a Administração Pública Brasileira de Batista (2012). Em relação ao primeiro Critério, Liderança em Gestão do Conhecimento, identificou-se que a instituição possui ações mal realizadas, de modo que há poucas iniciativas de promoção, reconhecimento e recompensa dos funcionários que apresentaram melhoria no desempenho, no aprendizado, no compartilhamento e na criação de conhecimento, isto acontece devido à inovação da alta gerência e às chefias intermediárias.

Dessa forma, constata-se a importância da UFSM desenvolver ações sistêmicas que promovam a identificação, geração, armazenamento, disseminação e utilização do conhecimento na organização, com mapas de conhecimento e registros que retenham a sabedoria essencial daqueles servidores que trocam de setor ou de instituição. Já as práticas de lições aprendidas, o compartilhamento de experiências e as técnicas de benchmarking devem ser utilizadas para que novos conhecimentos sejam criados, compartilhados e, assim, haja a melhoria no desempenho organizacional.

Em relação às práticas/iniciativas de compartilhamento de conhecimentos identificadas nos setores de trabalho destacam-se, dentre as principais: o compartilhamento de experiências; o diálogo e reflexão entre os servidores para criação de novo conhecimento; a participação em capacitações, cursos, eventos e palestras a respeito de temas de trabalho; e a leitura e interpretação de manuais, livros, normas, comunicados e documentos.

Com relação ao processo de flexibilização de jornada de trabalho e à análise dos constructos do Modelo de Batista (2012), constatou-se que não houve diferença significativa na percepção dos servidores, que aderiram ao processo de flexibilização de jornada de trabalho, daqueles que não aderiram. Ao comparar as médias obtidas entre os dois grupos pesquisados quanto à avaliação da gestão do conhecimento na instituição, identificou-se que os servidores que não possuem 
jornada flexibilizada consideraram a nota 5,44 ; enquanto que, para os que aderiram a flexibilização a média recebida foi de 5,37, em uma escala de zero a dez. Embora a diferença tenha sido pouco significativa, verifica-se que a implementação da jornada flexibilizada não criou uma política orientada para a geração e o compartilhamento do conhecimento nos setores de trabalho.

Esses resultados levam a refletir sobre como a flexibilização da jornada de trabalho repercute sobre a gestão do conhecimento. O primeiro ponto a destacar é que a manipulação da jornada de trabalho (ou seja, a não flexibilização) é essencial no que concerne à regulamentação e ao controle, principalmente do trabalhador, cuja atividade é rotineira e operacional. Em outras palavras, estipula o cumprimento de horas de trabalho mínimas ao trabalhador, que irá retornar através de atividades, as quais não exigirão dele um "pensar" sobre como desenvolver seu trabalho de forma mais efetiva. Este fato pode explicar em parte os resultados encontrados, pois, alguns dos servidores pesquisados executam atividades operacionais em grande parte do seu tempo, e ainda são pouco instigados a compartilhar seus conhecimentos.

O segundo ponto remete ao papel das universidades como difusoras e geradoras de conhecimento e como a flexibilização da jornada de trabalho pode ser útil. Ao dar mais autonomia ao trabalhador na gerência do seu tempo de trabalho, este pode realizar atividades complementares e interagir com outras pessoas com as quais não costumava se relacionar. Pode também ter mais flexibilidade para o convívio familiar e outras atividades culturais, recreativas, esportivas, etc. Dessa forma, como coloca Vignoli (2010), o trabalhador eleva seu nível de existência, aprimora seus conhecimentos e torna sua vida mais diversificada e atrativa, com mais possibilidades de ascensão profissional e social.

Ademais, o trabalhador (ou servidor público no caso deste estudo) não está focado e engajado na realização do seu trabalho exatamente no horário que the foi estipulado. Por isso, por mais que a flexibilização da jornada de trabalho não tenha resultado em um diferencial neste estudo, deve ser pensada de forma organizada e avaliada quanto ao seu impacto na gestão do conhecimento.

Essa pesquisa teve como limitação o tempo de aplicação, pois os questionários foram aplicados em uma época de férias para grande parte dos servidores. Além disso, alguns dos servidores convidados a participar relataram dificuldades de compreensão dos termos utilizados em relação ao tema, bem como de complicações para responder alguns itens por falta de alcance do conhecimento exigido em específico. 
Os resultados dessa pesquisa delimitam-se por se tratarem somente da percepção de servidores da Reitoria de uma instituição. Assim, sugere-se o estudo em outras unidades da UFSM, bem como em outras instituições de diferentes regiões do Brasil, a fim de se realizar uma pesquisa comparativa entre instituições federais de ensino. Além disso, como sugestão para estudos futuros, instiga-se pesquisadores da área a realizar pesquisas comparativas entre universidades em que há a flexibilização da jornada de trabalho para docentes e universidades em que não há essa flexibilização.

\section{REFERÊNCIAS}

Amayah, A. T. (2013). Determinants of knowledge sharing in a public sector organization. Journal of knowledge management, 17(3), 454-471.

Argote, L., \& Miron-Spektor, E. (2011). Organizational learning: From experience to knowledge. Organization science, 22(5), 1123-1137.

Batista, F. F. (2006). O desafio da gestão do conhecimento nas áreas de administração e planejamento das Instituições Federais de Ensino Superior (Ifes). Brasília: Ipea.

Batista, F. F. (2012). Modelo de gestão do conhecimento para a administração pública brasileira: como implementar a gestão do conhecimento para produzir resultados em benefício do cidadão. Brasília: Ipea.

Brasil (1988). Constituição da República Federativa do Brasil. Brasília. DF: Senado Federal. Recuperado de: <http://www.planalto.gov.br/ccivil_03/constituicao/ConstituicaoCompilado.htm>. Acesso em: 15 jul. 2016.

Collis, J., \& Hussey, R. (2005). Pesquisa em Administração: Um guia prático para alunos de graduação e pós-graduação. 2. ed. Porto Alegre: Bookman.

Felstead, A., \& Jewson, N. (1999). Global Trends in Flexible Work. London: Macmillan Pres Ltd.

Graham, N. (2010). Why Governments Need Guidelines for Risk Assessment and Management. In: Risk and Regulatory Policy: Improving the Governance of Risk. OECD, Paris.

Hartung, K., \& Oliveira, M. (2013). Communities of practice: creating and sharing knowledge. REGE-Revista de Gestão, 20(3), 407-422.

He, H., Baruch, Y., \& Lin, C. P. (2014). Modeling team knowledge sharing and team flexibility: The role of within-team competition. Human relations, $67(8)$, 947-978.

Heisig, P. (2009). Harmonisation of knowledge management-comparing $160 \mathrm{KM}$ 
frameworks around the globe. Journal of knowledge management, 13(4), 4-31.

Jinkings, N. (2002). Trabalho e resistência na "fonte misteriosa": os bancários no mundo da eletrônica e do dinheiro. Campinas, SP: Editora da Unicamp.

Nonaka, I.\& Takeuchi, H. (1997). Criação do conhecimento na empresa. Rio de Janeiro: Campus.

Pokharel, M. P., \& Choi, S. O. (2015). Exploring the relationships between the learning organization and organizational performance. Management research review. 38(2), 126-148.

Ramayah, T., Yeap, J. A., \& Ignatius, J. (2014). Assessing knowledge sharing among academics: A validation of the knowledge sharing behavior scale (KSBS). Evaluation review, 38(2), 160-187.

Sabherwal, R., \& Becerra-Fernandez, I. (2003). An empirical study of the effect of knowledge management processes at individual, group, and organizational levels. Decision sciences, 34(2), 225-260.

Ventura, M. M. (2007). O estudo de caso como modalidade de pesquisa. Revista SoCERJ, 20(5), 383-386.

Vignoli, V. A. (2010). Flexibilização da jornada de trabalho: importância e limitações. 100 f. (Dissertação de Mestrado em Direito do Trabalho). Universidade de São Paulo - USP, São Paulo, Brasil.

Wig, K. M. (2000). Application of knowledge management in public administration. Taiwan: ROC. 